\title{
Myles Brand: Intercollegiate Athletics Within the Limits of the Academic Mission Alone
}

\author{
Lou Matz \\ University of the Pacific
}

If we are to restore the proper role of intercollegiate athletics we must make an absolute commitment to the academic mission and integrity of the university. --Myles Brand ${ }^{1}$

In his Religion Within the Limits of Reason Alone, the German philosopher Immanuel Kant argued that religious belief must be bound solely by reason and the human conditions of experience in our spatio-temporal world. Religious beliefs that transcended these conditions were unjustifiable and, more importantly, could easily motivate what Kant characterized as a fanatical pseudo-service to God that led to superstition, persecution, and violence. Legitimate or enlightened religious belief must operate within the bounds of reason and morality, which led Kant to heterodox views on Christianity, such as Jesus was a human moral exemplar and not a divine being and living a moral life alone is sufficient for any reward in a possible afterlife.

One of Myles Brand's longest-standing convictions about intercollegiate athletics (IA) was that it must be bound solely by the academic mission and values of a university or become an unjustifiable activity. When IA is guided by commercial values or winning as the summum bonum, it easily leads to what might be called a fanatical 'pseudo-intercollegiate athletics,' a neglect or outright repudiation of academic values that can easily motivate academic and financial scandals. Legitimate or enlightened IA must operate within the bounds of the academic mission and educational values of a university, which led Brand to the heterodox view that IA should be reconceptualized as an educational activity that is essential to the academic mission of universities. As the first National Collegiate Athletic Association (NCAA) President to be a former faculty member and university president, Brand's view of the role of IA in universities had unique credibility.

During his presidency, Brand led novel academic reforms in IA that gained deserved public recognition, such as increasing high school academic requirements to play IA and the establishment of the Academic Progress Rate (APR) that produced higher student-athlete graduation rates. Nevertheless, his defense of the educational and academic value of IA should be equally acknowledged since this was, for Brand, 
the ultimate reason why universities should support IA in the first place: "the underlying reason why universities support intercollegiate athletics is that it provides educational value for those students who participate" (Brand, 2009, p. 7). To those critics who contended that because universities are academic institutions and athletic participation is not 'academic' and so IA does not belong there, Brand countered by offering a broader view of a university education that included not only formal learning objectives but the development of character virtues that take place outside of the formal academic curriculum and that are essential to a productive life in one's community and as a citizen, virtues that IA can develop. In this way, Brand held that IA should rightly be considered to be part of the academic mission. Brand made his most forceful and elaborate defense of the educational value of IA in his 2006 article "The Role and Value of Intercollegiate Athletics in Universities." This article represents the fruition of Brand's thinking on the topic since it is here where he developed what I believe is his most distinctive defense of the academic value of IA: its similarities to performing arts such as dance and music.

In section I, I describe Brand's developing view of the educational value of IA that preceded his signature 2006 article. Articulated when he was President of Indiana University and subsequently as the new President of the NCAA, Brand proclaimed the necessity of IA's relationship to the educational and academic mission, but he did not give many details about this relationship and was in the process of developing what would become his 'Integrated View.' In section II, I explain Brand's Integrated View and focus on his key argumentative strategy: the analogy of the educational value of IA to the educational value of performing arts like music and dance. In section III, I argue that Brand did not bring his analogical argument to its full logical conclusion, namely, that IA should contribute to a bona fide academic major in Sports Performance or Competitive Sport. Moreover, Brand could have appropriated a contemporary vision of liberal learning outcomes that includes some of the very character virtues that Brand identified as inherent in IA, hence relocating them from the sphere of what he termed "developmental aspects of character" (Brand, 2009, p. 7) to actual 'academic' learning outcomes. The result is that Brand's defense of the educational value of IA can be strengthened based on the premises of his own reasoning. I conclude by raising some criticisms of Brand's view based on the organizational framework and policies of IA that create difficulties for the full realization of its educational value. ${ }^{2}$

\section{Section I: Developing the Educational Argument for Intercollegiate Athletics}

Based on public speeches that he gave before the publication of his 2006 article on the role and value of IA in a university, Brand had a strong conviction that IA must contribute to the academic mission of the university, and he was thinking through the types of reform that would align with this goal. Indeed, there were different ways that, or different degrees to which, IA could align with the academic mission. Brand thought both about removing existing obstacles as well as novel integrative 
approaches: there could be higher academic standards for eligibility, there could be annual completed unit standards to progress toward graduation, athletic academic and advising services could be incorporated into these university services for all students, there could be less required athletic participation to create more time for study, coaches could be hired who valued developmental values for their players as much as winning, and there could be formal recognition by faculty and academic administrators of the educational value of IA.

Just over four months after he, as President of Indiana University, fired controversial basketball coach Bobby Knight, Brand gave a speech to the National Press Club titled "Academics First: Reforming Intercollegiate Athletics." Here, he rejected two extreme and unrealistic solutions to the educational problems created by the commercialization of IA, primarily in the elite athletic programs with football and men's basketball: eliminating IA and athletic scholarships and replacing them with student-led club sports or, alternatively, professionalizing them. For Brand, these remedies neglected the benefits of IA on campus when "conducted well and with good sense" (Brand, 2001, p. 369), such as strengthening connections among the community, students, faculty, and alumni, providing economic benefits to the local community, and, for those programs that generated sufficient revenue, financing nonrevenue sports, including women's sports. Brand did not believe that the professionalization of IA - paying college athletes directly — was a realistic and appropriate possibility. For Brand, the goal was not to dismantle IA but "limit its excesses so that its positive features can flourish" (Brand, 2001, p. 369). Nonetheless, for Brand these positive features were not enough to justify IA since it must ultimately serve a university's academic purpose and not merely be an ancillary service, such as providing entertainment. He stated, "if we are to restore the proper role of IA we must make an absolute commitment to the academic mission and integrity of the university" (Brand, 2001, p. 369). But in this speech, Brand does not articulate how IA can serve the academic purpose other than not to interfere with it by improving graduation rates. In other words, he does not identify the educational value of IA but only exhorts presidents, trustees, directors of athletics, and conferences to commit to the "primacy of academics, despite the daily pressures of the athletic community and boosters" (Brand, 2001, p. 369).

But what did Brand believe were the academic purposes of a university? His view was conventional and, I believe, more representative of the research-oriented universities where he had been President: to "discover, apply, transmit and preserve knowledge" (Brand, 2001, p. 369). His definition is worth reflecting on for two reasons. First, Brand stated that any university activity must at least indirectly serve these purposes and not interfere with them (Brand, 2001, p. 369). Secondly, Brand's definition of a university's academic purposes was one-sided since it stemmed solely from a faculty perspective - to discover, apply, transmit, and preserve knowledgerather than from a student learning perspective, where IA can be aligned with the academic mission. This is Brand's approach in his 2006 article.

It is also worth noting from Brand's "Academics First" speech that he provocatively claimed that "the athletic department cannot be separated, organizationally or 
in attitude, from the academic side of the institution" (Brand, 2001, p. 369). However, he did not elaborate on this reform principle and its implications. Did he mean to imply that Athletics should report to Academic Affairs, or merely to reinforce the recommendations by the Knight Commission reports on the necessity for university presidents to have control of Athletics? Or that directors of athletics and coaches must be hired who share the "attitude" of the academic side of the value the life of the mind and academic study? Brand returned to this organizational issue in his 2006 article.

It is in Brand's first state of the NCAA address in 2003 that he began to articulate the educational value of IA. He identified five foundational principles to guide the strategic planning of the NCAA: integration of IA into the academic mission, presidential control of IA, advocacy of the positive value of IA, preservation of amateurism, and the importance of fairness and just action in IA. In this speech, to integrate IA into the academic mission meant that "intercollegiate athletics must accommodate itself to the academic priorities of universities and colleges, and not vice versa" (Brand, 2003, p. 4). For Brand, students must train in athletic cultures that encourage them to take advantage of educational opportunities, such as access to all majors and adequate time to study. But it is in the context of the third foundational principle - the "positive value" of IA - that Brand described its educational value, for he claimed that IA created opportunities "to internalize the values of hard work, fair competition and cooperation toward a common goal ... loyalty, fairness, self-respect, respect for others and a quest for excellence" (Brand, 2003, p. 5).

In his 2005 State of the Association address, Brand focused on a different dimension of the alignment of athletics with the academic mission than in his 2003 address - not the educational value of IA but new academic reforms designed to improve graduation rates, namely, stronger high school academic requirements to play IA and required yearly academic unit completion targets or APR. Brand attempted to debunk the myth that student-athletes dedicated much more time on developing their athletic skills than getting an education by giving empirical evidence of higher graduation rates among athletes than the general student body, though he acknowledged that the myth persists due to the lower graduation rates for football and men's basketball. In response to the perceptions that athletes took easy courses or completed easy majors (so-called 'clustering'), Brand admitted there was some evidence for these claims, but he directed the criticism at its proper source of responsibility: the faculty who have the authority to approve courses and majors in the academic curriculum and assign grades. As a former faculty member, he was a credible insider critic.

In Brand's 2006 State of the Association Centennial address, Brand did not give any attention to the educational value of IA. He described first axioms that should guide IA: the acquisition of a college education and realization of full academic potential, compliance with NCAA rules that engender fairness of competition, commercial practices that do not detract from the academic opportunities, business activity that is guided by the values of higher education, and a commitment to the ideal of a meritocracy (Brand, 2006a). Brand's preoccupation in his address was the increasing threat that commercial realities of IA posed to the educational opportunities of 
student-athletes. To make the case that IA can be conceptualized as an educational activity itself would temper the threat and lead faculty and academic administrators to embrace IA's academic value within a university's mission and more willingly accept its financial support by the university's general fund. This is what Brand tried to accomplish in his 2006 article.

\section{Section II: Brand's Integrated Ideal of Intercollegiate Athletics}

In his 2006 article "The Role and Value of Intercollegiate Athletics in Universities," Brand finally gave his full attention to how IA can be integrated with the academic mission of the university, rather than merely align with it, such as developing virtues like hard work, commitment toward a common goal, and respect for others or, more minimally, not detract from it, such as by improving graduation rates (Brand, 2006b). That Brand produced a scholarly article amid his responsibilities as the President of the NCAA was remarkable, and he would refer to his fundamental critique of faculty attitudes toward IA in later articles and talks. ${ }^{3}$ For Brand, integration was the goal and ideal, combining IA with academic study to create a unified educational experience. His appeal to 'integration' hearkened back to the beginning of the NCAA's mission in the early $20^{\text {th }}$ century, referenced in his penultimate annual State of the NCAA speech where "intercollegiate athletics are to be an integral part of higher education and the student-athlete an integral part of the student body" (Brand, 2008a, p. 1, emphasis is mine).

Brand's focus and audience in the article were specific. His purpose was not to defend the organization or system of delivering IA from long-standing criticisms and critics, though he claimed many of the criticisms were false or exaggerated and others were being rectified by new reforms. Rather, his principal purpose was to explain how IA "has the potential to contribute far more to the academic enterprise than it does currently" (Brand, 2006b, p. 9). Brand's targeted audience was the very same group whose misperceptions prevented IA from being properly understood: the faculty and the academy at large.

To explain his 'integrated' view of IA, Brand first described what he characterized as the 'standard' view. Held primarily by faculty and academic administrators, the Standard View of IA is that it is not part of the academic and educational mission of universities; rather, it is extracurricular, and its elimination would not detract from the university mission. Universities are devoted to the discovery and dissemination of knowledge and the different disciplinary methods of knowing, and students are to learn the content of areas in academic disciplines and develop cognitive skills to understand and apply them, such as analytical reading skills, written and oral communication, and critical thinking. IA might develop worthwhile virtues such as hard work, persistence, teamwork, and leadership, but its elimination would not detract from the educational mission and would, in fact, strengthen it by removing an unnecessary distraction. IA is no more related to the educational mission than activities of student clubs or Greek life. 
Brand's first reaction to the Standard View was to bring out the bias against the educational value of IA by comparing the academic standing of musical performance to the non-academic standing of athletic performance. He identified three types of relevant similarities between music performance majors and IAs that exposed the academic bias against IA - shared experiences, demonstration of 'practical' skills through performance, and the development of similar values or character virtues. First, he identified student experiences that athletes and performing art students have in common to demonstrate that there are no substantive differences between them: students must be accomplished for a highly competitive admission process; some with exceptional talent are admitted even with below normal qualifications; there are auditions (in the case of athletics, coaches watch athletic competitions or athlete videos); there are many hours of practice, in and out of class, that are year round; there are public performances; students formally represent the university; there are ambitions for professional careers that are highly competitive; and, based on the amount of time spent together on and off campus, students form much stronger bonds with their performance instructors and coaches than with typical faculty. Second, unlike the study of physics or philosophy, Brand described IA and the performing arts as exhibiting not only factual knowledge or theoretical understanding but the demonstration of knowledge or understanding through action or praxis. This distinction between theoretical and practical knowing was described by Gilbert Ryle as the difference between knowing 'that' and knowing 'how'. For example, music students gain both knowing 'that' through music theory and history and knowing 'how' through practice and public performances. The same is true for intercollegiate athletes. They understand concepts of technique and strategy and perform or exhibit them in practice and competition. Finally, Brand identified various character virtues that are inherent to the ideal of athletic participation, such as "striving for excellence, perseverance, resilience, hard work, respect for others, sportsmanship and civility, and losing and winning with grace" (Brand, 2006b, p. 17). Many of these virtues are cultivated in the performing arts and are an important part of the character or whole-person development of students. Brand concluded his analogy by stating, "given this convergence, it might be expected that the student-athlete experience and that of students in the performing arts would have similar academic standing, but that is not the case" (Brand, 2006b, p. 11).

For Brand, the principal reason for this disparate treatment is that what has counted as legitimate 'academic' study has traditionally been limited to purely intellectual or cognitive skills, not physical skills or skills of physical movement. Legitimate academic activity involves learning factual content in disciplines, methodological ways of thinking, and the development of the necessary cognitive skill to demonstrate these, such as reading, writing, critical thinking, and conducting research. Brand stated, "for the most part, faculty members hold intellectual powers in higher esteem then they do bodily abilities. Put provocatively, the American academy is prejudiced against the body" (Brand, 2006b, p. 14).

Brand's Integrated View of IA is based on the assumption that the development of physical skill is worthy of inclusion as part of a university education. Bias against the value of the display of skill through the body prevents such inclusion. The history 
of academic tradition notwithstanding, why should the development of the body and skilled physical movement not be a legitimate academic activity of study and performance? Brand rightly noted that the purposes of a university education have become more practical over time. This reform orientation began in the mid- $19^{\text {th }}$ century with the founding of U.S. land grant universities devoted to practical know-how and new 'professional' majors, such as agriculture and engineering. So for Brand, while there had been a higher education tradition that values bodily skills leading to a vocational or non-liberal arts approach to university education, there is also an entrenched bias against bodily or physical skills, especially among liberal arts faculty.

Brand returned to his analogy to the performing arts to conclude his account of the Integrated View by noting that "although they [athletics] are not part of the liberal arts core, they play the same type of role as music and art and, perhaps, business and journalism" (Brand, 2006b, p. 17). In defense of his view, Brand alluded to Plato's educational ideal in his Republic of combining intellectual (musical) and physical (gymnastic) training to form a harmonious, integrated person and a complete political leader. And Brand pointed out that, unlike in the rest of the world, physical education has been an integral component of the United States' primary and secondary educational system and so should be assimilable as "a valuable part of the educational environment” (Brand, 2006b, p. 17) in higher education.

Brand emphasized that his defense of IA on the grounds of its development of physical skills, or what can be more precisely described as skills of physical movement, was different than the common educational defense of IA, which focused on the development of cognitive skills and habits that supported or transferred to academic learning, such as critical thinking and problem solving, where playing a sport well involves "observation, weighing alternatives, assessing probabilities, and hypothesizing solutions" (Brand, 2006b, p. 12). While Brand did acknowledge the truth of this perspective, his decided focus was on the academic bias toward cognitive skills and rejection of physical skill development as appropriate to university education.

Brand concluded his account of the Integrated View by drawing out some of its implications. He noted that given the relevant similarities between music and athletic performance, athletes should receive academic credit for participating in IAs. However, Brand resisted the implication that there should be majors in basketball or other sports, though he never explained the reasoning for his assertion. I address this issue in the next section. Reiterating the statement in his 2001 'Academics First' speech, Brand contended that Athletics and Schools of Music should have the same reporting line in the university's organizational chart and that directors of athletics should have a similar role as deans. He held that the director of athletics should report directly to the president and be part of the presidential cabinet, yet Brand's view here appears to contradict his own claim since deans report to academic vice presidents, not presidents, and Schools of Music are part of Academic Affairs. His view became more unclear when he, in the very same year, praised Vanderbilt University for its progressive decision to have its Director of Athletics report to the Vice President of Student Affairs to integrate athletics better into the university (Brand, 2006c, pp. 45-46). 


\section{Section III: Expanding Brand's Integrated Ideal}

Brand's defense of the educational value of IA based on the similarities to the performing arts is compelling. He identified educationally relevant similarities between the two types of activities, especially the practical 'know how' skill of performing and the types of personal and social character virtues that these activities can develop. Those who have attempted to challenge the logical strength of the analogy have not made a persuasive case (Feezell, 2015). However, Brand's analogy would have been strengthened had he used dance performance, rather than music performance, as his primary comparison since it involves skill of physical or bodily movement that is a more comparable to athletics. Nevertheless, Brand unwittingly planted the theoretical seeds in his article that warrant having IA contribute directly to a new academic major and hence to better fulfill his desideratum that IA be as central to the academic mission as possible. As he rightly noted, there was a time in U.S. higher education when music and dance were not part of the academic curriculum, but academic attitudes evolved to establish these extracurricular and performance-oriented activities as legitimate academic majors. Brand pointed out that these new attitudes were part of 'practical' or 'pragmatic' educational reform movements that began in the United States in the mid-nineteenth century. He referred to this 'distinctly American' practical approach in U.S. universities, which he contrasted with the mostly theoretical and research-oriented German universities, yet "despite this practical, skill-oriented history of American higher education, the intellectual, cognitive approach prevails. In it, emphasis on bodily skills is inappropriate; indeed, it subverts the true aim of the university" (Brand, 2006b, p. 14).

So, despite the facts that (1) there are various relevant learning similarities between IA and performing arts; (2) former extracurricular 'performance' activities that include the practical demonstration of physical skills, such as music and dance, became bona fide academic majors; and (3) there has been a continuing and influential pragmatic curricular reform tradition in universities and colleges, Brand did not bring his arguments to their logical conclusion: IA should contribute to a new, firstof-its-kind Sport Performance or Competitive Sport major. I have extended Brand's argument to this logical terminus in my article "Turning Competitive Athletics Into a Performance Major Like Music" by describing the curricular requirements, program learning objectives, and advantages of this type of potential new major (Matz, 2020). Brand explicitly dismissed the notion of majoring in sports like basketball or other sports (Brand, 2006b), but his haste in doing so is unclear. He pointed out that only those physical activities that are 'artistic' and 'relate to high culture' are considered liberal arts, which is why ballet and classical music qualify, but football and rock-nroll do not (Brand, 2006b). Given the context and tone, Brand appeared to be critical of these distinctions and so was not defending the academic status quo.

Similar to a Music Performance major where a specific performance focussuch as piano or percussion or saxophone or voice - is combined with a music-related curriculum, a Competitive Sport major would combine a 'performance' concentration in a particular NCAA or select Club sport with a sports-related curriculum. 
Here, in Table 1, is one possible type of Competitive Sport curriculum with corresponding learning objectives ${ }^{4}$ :

Table 1

Competitive Sport Curriculum and Learning Objectives

\begin{tabular}{|l|l|}
\hline Required Courses & Learning Objectives \\
\hline Intercollegiate or Club Sport (3 years) & Sport-specific Objectives \\
\hline Principles of Exercise Physiology & \\
\hline Nutrition and Metabolism & \\
\hline Sport Analytics & \\
\hline Sport Psychology & Critical Thinking \\
\hline Global History of Sport & Written Communication \\
\hline Legal \& Policy Aspects of Sport & Oral Communication \\
\hline Philosophy of Sport & Intercultural Understanding \\
\hline Public Speaking & Teamwork \& Leadership \\
\hline Sport Management & Ethical Reasoning and Conduct \\
\hline Principles of Coaching and Leadership & \\
\hline Internship & \\
\hline Integrative Capstone Project & \\
\hline
\end{tabular}

The sport-specific objectives would be defined by the coaching staff. The other learning objectives would be defined by faculty with input by the coaches. Several of these learning objectives could be addressed by both faculty and coaches. The program would be directed by a faculty member and administered in an academic unit. The establishment of such a Competitive Sport major would more fully realize Brand's long-held conviction that IA must be a part of the academic and educational mission of universities and colleges.

Aside from the analogical curricular frameworks that music performance and dance programs provide for a Competitive Sport major, Brand was also apparently unaware when writing his article of a contemporary pragmatic vision of liberal learning objectives that could have strengthened his case for the academic value of IA, one espoused by the preeminent national organization devoted to undergraduate liberal learning, the Association of American Colleges and Universities (AAC\&U). ${ }^{5}$ In collaboration with the business sector, community organizations, and university leaders, AAC\&U has identified through its Liberal Education and America's Promise (LEAP) initiative essential learning outcomes for a $21^{\text {st }}$ century liberal education. Among these outcomes are ones that Brand identified in IA: teamwork and problem solving, intercultural knowledge and competence, ethical reasoning and action, and integrative and applied learning. ${ }^{6}$

In an article that was the basis of what would be his last State of the NCAA annual address in 2009, Brand articulated his most elaborate description of a complete university education, but he did not realize that what he characterized as the "developmental aspects of character" as well as the purposes for this character development had already been conceptualized as academic learning outcomes and goals in AAC\&U's pragmatic conception of liberal learning. Brand stated: 
The primary role of a university education is to create learning opportunities in academic disciplines, such as physics, psychology and philosophy. It is also designed for certain skill development, such as computer literacy and cultural understanding. But a complete university education goes beyond these areas; it also includes the development of character that enables one to be a successful adult, someone who is capable of having a good family life, who is a contributor to his or her community, and who is a productive citizen. These developmental aspects of character are taught through participation in athletics. There are, of course, other ways to learn character at the university. But, I contend, there is no better way than through athletics participation (2009a, pp. 6-7).

Here, Brand distinguished three types of educational experiences that universities ideally should formally foster: learning the content of an academic discipline, learning certain skills, and developing character virtues. The purposes of the latter are to become an effective member in private life, in one's community and as a citizen, goals that AAC\&U also identified as essential to $21^{\text {st }}$ century liberal learning.

Brand's argument for the academic value of IA can be extended even further. Playing an intercollegiate sport can plausibly be considered as a type of liberal art. Interestingly, Brand claimed that although IA can play the same type of educational role as music and art, it is "not part of the liberal-arts core" (Brand, 2006b, p. 17). From this statement, it appears that Brand believed that there was a relevant difference between types of performance-based physical skills, though he earlier appeared to criticize the academic distinction between high and low artistic forms. But here again, Brand did not realize the possibilities of his argument. Based on traditional understandings and the historically evolving pragmatic orientation of the liberal arts, the following reasons can justify reconceiving the playing of a competitive sport as a liberal art: it (1) liberates human powers of the body and displays its excellences or virtues; (2) creates profound opportunities for self-reflection and self-knowledge; (3) develops contemporary liberal arts skills such as teamwork and problem solving, intercultural competence, ethical reasoning and action, and integrative and applied learning; (4) provides a general condition of physical and mental health, which is useful for all kinds of specific occupations, the original meaning or criterion of the four liberal arts in Plato's ideal education in the Republic, ${ }^{7}$; and (5) contributes to the formation of a holistic, integrated person. ${ }^{8}$ In his defense of IA as a type of performing art, Brand laid the foundation for these additional defenses of the educational value of IA, which would have fully satisfied his requirement that IA be integrated with the academic mission of the university.

\section{Section IV: The Impact of the Organization IA on its Educational Value}

During his NCAA Presidency, Brand spoke and wrote often on the increasing conflict between educational and commercial values, especially for highly commercialized athletics programs with football and basketball. This was the theme of what 
would be his final 2009 State of the Association address, and it is revealing that he began his 2006 article by describing the detrimental effects of this problem before shifting his focus to the educational value of IA. Nonetheless, Brand's Integrated View of IA required much more examination of the educational harms that the organizational delivery of IA created, and I contend that he minimized the extent and intractability of the following problems due to both the commercialization of IA as well as professional ambitions of the key administrative stakeholders in IA, such as presidents, conference commissioners, directors of athletics, and coaches:

1. the amount of missed class due to IA

2. the required amount of time commitment to IA in and out of season

3. the hiring of coaches who do not genuinely value academic study and life of the intellect.

In his article "Faculty Members' Constructive Engagement in Intercollegiate Athletics," Brand acknowledged two regular faculty complaints about how IA conflicts with academics: the amount of class that student-athletes miss, which is much more than those who are musicians or debaters, and the burden placed on faculty to accommodate athletes, who might need to give student-athletes additional instructional time or to create separate assignments (Brand, 2007a, pp. 14-15). Rather than examine these problems and offer recommended remedies, Brand focused on defending missed class as a legitimate excused absence and the unfairness of faculty who penalize students due to the requirements of participation. However, the problem of missed class time raises the contentious issues of who has the authority to determine missed class policy and how much missed class is acceptable.

On the one hand, I agree with Brand that athletes should not be penalized academically for fulfilling their university IA obligations, and faculty should realize that there are legitimate institutional-level commitments that might sometimes conflict with their courses. However, why should IA and their conferences have the authority to dictate to faculty how much class student-athletes will miss, especially when the amount is extensive? In his 2005 State of the Association address, Brand stated "the academic integrity of an institution is primarily in the hands of the faculty. They create and approve the courses and curriculum, and they set the standards for instruction" (Brand, 2005, p. 4, emphasis is mine). The burden should be on athletic conferences and athletic programs to create competition schedules and an IA culture that absolutely minimizes the amount of time athletes miss class. For example, the athletic department at my mid-major D-1 institution, which does not have an IA football program, aspires to have students miss no more than $15 \%$ of any course in a semester, and most athletes do not approach that limit, though in some years some teams exceeded it. Why shouldn't the limit be 5 or $10 \%$, and why shouldn't the authority to adopt a sensible limit be a result of a collaborative process involving the faculty, academic vice presidents, presidents, and directors of athletics?

Brand also never gave sufficient attention to the amount of IA athletic practice time in and out of season. This is a foundational issue for the healthy and sustainable 
integration of IA with academic study, even if IA is embraced by the academy as an academic experience. The only significant mention of this issue by Brand that I could find was his Mondays with Myles episode "Aristotle's Golden Mean" (Brand, 2007b). Here, he stated that a limit of 20 hours per week in season seemed to be about the right amount between an extreme and a deficiency, the two poles that frame the Aristotelian mean to define a character virtue. But Brand gave no principled argument for this limit, e.g., by comparing IA participation to a half-time job or basing the amount on the typical 20-hour limit for student federal work study. Brand only noted that the 20-hour limit seemed too little for some critics and too much for other critics but left it at that. Moreover, Brand omitted key facts from his brief analysis. First, the 20-hour limit does not include other time that student-athletes need to commit to IA, such as treating injuries and travel time to competition. Additionally, the 20-hour limit is often de facto transgressed by athletes due to factors like the pressure they might feel from coaches or the program culture to improve or to earn more playing time.

Brand also gave too little attention to one of the most vital factors in the integration of IA with the academic mission: the academic orientation of coaches. When he did refer to coaching issues in his State of the Association speeches and elsewhere, Brand focused mostly on the lack of women and minority coaches in IA. His most elaborate discussion of coaches' orientation and responsibilities appeared to be his Mondays with Myles episode "Winning \& Losing” (Brand, 2007c). Here, Brand described the importance of coaches as teachers and mentors who impart "life skill values" such as "seeking excellence, persistence, hard work, team work" (Brand, 2007c, p. 217). He stressed the ethical commitment that university athletic programs and coaches have to recruit athletes who are prepared enough to succeed academically and to provide proper academic support. He agreed with the interviewer that if academic success matters, more coaching contracts should be structured to reward team academic performance and not solely competitive success (Brand, 2007c, p. 220). Yet, Brand frankly acknowledged that in "the real world" (Brand, 2007c, p. 218), coaches get hired and fired to win, and he rejected the adage 'It's not whether you win or lose but how you play the game' since winning is, in fact, important, though it must be done in the right way (Brand, 2007c, p. 218).

However, the episode leaves one with the impression that Brand minimized what appears to be an intractable conflict between commercial interests and educational priorities, particularly at the highly commercialized IA programs. If a coach's win-loss record is what ultimately matters in hiring and firing, they are incentivized to recruit, above all, the most talented player, not one who will also be academically well-prepared or motivated by the enjoyment of academic study. And it will always be a temptation to risk getting caught for violating policies for competitive success, even for highly respected academic institutions. It is also telling that among the "life skill values" that Brand identified coaching imparts, he did not mention the value of the life of the mind. This is a conspicuous oversight since this would be an impactful way for coaches to integrate with the academic mission. In addition, when Brand talked about the necessity of coaches' commitment to academic success, he did not 
describe the deeper levels of academic success that faculty generally recognize as paramount. For example, do coaches create an athletic culture that values the life of the intellect and academic study? Will they support players who want to miss practice to attend exam study sessions or intellectual activities on campus? Do they inspire their players to take demanding classes to challenge themselves intellectually? These questions are heightened by Brand's frank acknowledgment that coaches are hired to win since commercial success depends on it, and commercial success is necessary to subsidize IA, especially non-revenue generating sports.

I conclude with Brand's view of amateurism and its relationship to the educational mission of universities since his defense of amateurism was ultimately based on the educational value of IA and the amateur status of intercollegiate athletes is being challenged legally as never before in NCAA history. Unlike professional sports, Brand maintained that IA is ideally to be an educational complement of academic study and the campus educational experience. Brand thought it was a distinctive strength of U.S. universities that IA was part of the educational experience, unlike any other universities in the world. As a practical reality, he advocated that IA must be commercialized to finance itself, but the business enterprise of IA must always be conducted within the educational values and ethical integrity of the university. To professionalize IA is to misunderstand its fundamental educational purpose and direct it away from educational goals to making a living.

However, one can draw a different logical conclusion from his premises than Brand did. To professionalize IA by allowing athletes to profit from the use of what is now called their name, image and likeness (NIL) could give them a powerful real-world educational opportunity to learn about the business side of sports, and so professionalizing IA could better support educational goals. It is relevant to note in this regard that business is the most popular major for intercollegiate athletes. ${ }^{9}$ So even if one grants Brand's questionable assumption that student-athletes are amateurs solely because their motivation to play is "for its own value, the feeling of pride in the competition itself" (Brand, 2003, p. 5) or "for the love of the game" (Brand, 2005, p. 10) or "as part of their overall education, not as professionals" (Brand, 2009, p. 4) - which distinguishes them from professional athletes - compensating them for the use of their name, image and likeness would nevertheless give them a real experiential learning opportunity.

One can also logically appeal to Brand's insistence on "fair and just action in intercollegiate athletics" (Brand, 2003, p. 6) to defend student-athlete payment not only for the use of their NIL but also for those few student-athletes who generate more revenue than the costs of their program. Brand opposed this option. In his "Why the Fairness Argument on Pay for Play Isn't a Fair Argument," Brand argued that it has always been true in IA that others involved in the IA enterprise besides the student-athletes have been paid. In reply to those who defend payment to those "few elite athletes in one of the two sports [football and basketball] at one of the dozen or less institutions that are "big time" enough to consistently generate more revenue than required to pay the bills" (Brand, 2008b), Brand countered that there would be the charge of unfairness by those athletes who are not getting paid and by those 
whose non-revenue sports are supported by football and basketball. However, these arguments are not too persuasive since the former begs the question in its reliance on historical tradition, and the latter does not plausibly identify the alleged unfairness to others.

In the end, Brand used his faculty and university president experience to articulate a view of the educational value of IA that faculty and the academy could embrace as part of the academic mission. His view was both principled and pragmatic. Based on the documentary record, Brand never appeared to formulate a specific plan to promote intentional conversations at universities by presidents and faculty athletic representatives to gain acceptance of his Integrated View. Unless one read his 2006 article, there was not enough regular emphasis in his speeches, writings, and interviews on the educational value of IA to widen the exposure of his Integrated View. I am also unaware of any survey data of faculty perceptions on the educational value of IA and its relationship to institutional mission. The status of the impact of Brand's Integrated View on faculty attitudes about IA is thus difficult to assess. Nevertheless, as I have argued above, since Brand's educational ideal of IA can logically be extended to contribute to a Competitive Sport major, the establishment of such a major would directly connect IA with the academic mission, and the spread of such majors could have a significant impact on changing faculty perspectives on the legitimate place of IA in universities. At a momentous time in U.S. higher education when university priorities and budgets are under perhaps unprecedented scrutiny, Brand's insistence that IA must be integrated with the academic mission is more relevant than ever.

\section{Acknowledgements}

I would like to thank the co-editors of this special JIS issue for their excellent feedback on an earlier draft. I also thank my colleague and friend Gene Pearson for his suggestions on that draft as well as our conversations about it during our walks around Victory Park in Stockton.

\section{Notes}

1. Brand (2001).

2. While Brand's analysis of the educational value of IA applies to all NCAA divisions, his target audience is mostly Division I.

3. For example, see Brand (2007b) and https://www.hamilton.edu/news/story/ ncaa-president-myles-brand-speaks-on-the-place-of-intercollegiate-athletics-inamerican-culture

4. See Matz (2020).

5. Brand's lack of reference to AAC\&U's liberal learning outcomes is intriguing since he was a member of the LEAP National Leadership Council and listed his 2006 participation in a $\mathrm{CV}$. 
6. See https://www.aacu.org/essential-learning-outcomes. AAC\&U released its first version of the Liberal Education Outcomes in 2005, which were renamed Essential Learning Outcomes in its 2007 publication College Learning for the New Global Century.

7. While Brand invoked Plato's educational ideal of combining intellectual and physical training to defend his educational defense of IA, he did not appreciate other aspects of Plato's account of the value of physical training for the development of the intellect, e.g., Plato held that rigorous bodily or gymnastic training, which included athletic contests, developed the endurance and spiritedness (courage) needed to persist with the abstract and rigorous ruler education in mathematics, geometry, astronomy, and dialectic. See Plato, The Republic, 537b.

8. I develop this argument in an article that is scheduled to appear in the spring 2022 edition of Liberal Education titled "Playing Competitive Sport as a Liberal Art."

9. According to the NCAA's most recent data, $25 \%$ of student-athletes majored in Business in 2017-18. See https://www.ncaa.org/about/resources/research/divisioni-diploma-dashboard

\section{References}

Brand, M. (2001, January 23). Academics first: Reforming intercollegiate athletics. Address delivered to the National Press Club, Washington, D.C.https://mylesbrand.com/wp-content/uploads/2001/01/National-Press-Club-2001.pdf

Brand, M. (2003, January 1). State of the Association Address. https://mylesbrand. com/wp-content/uploads/2003/01/2003-NCAA-State-of-the-Association.pdf

Brand, M. (2005, January 8). The myths of college sports: Debunking the four great commonly held misperceptions about intercollegiate athletics. State of the Association Address. https://mylesbrand.com/wp-content/uploads/2005/01/2005-NC AA-State-of-the-Association.pdf

Brand, M. (2006a). The principles of intercollegiate athletics. State of the Association Address. https://mylesbrand.com/wp-content/uploads/2006/01/2006-NCA A-State-of-the-Association.pdf

Brand, M. (2006b). The role and value of intercollegiate athletics in universities. Journal of the Philosophy of Sport, 33(1), 9-20.

Brand, M. (2006c, March). IMM and Myles Brand. Indy Men's Magazine, 45-51.

Brand, M. (2007a, Spring). Faculty members' constructive engagement in intercollegiate athletics. The Montana Professor, 17(2), 14-18.

Brand, M. (2007b, April 9). Mondays with Myles. Aristotle's Golden Mean, Episode 51. https://mylesbrand.com/wp-content/uploads/2007/01/4-9-2007-Aristotles-Golden-Mean.pdf

Brand, M. (2007c, September 17). Mondays with Myles. Winning and losing, Episode 73.https://mylesbrand.com/wp-content/uploads/2007/01/9-17-2007-Winning-Losing.pdf 
Brand, M. (2008a, January 12). Leadership and challenges: The roles of intercollegiate athletics in the university. State of the Association Address. https://mylesbrand.com/wp-content/uploads/2008/01/2008-NCAA-State-of-the-Association.pdf

Brand, M. (2008b, September 12). Why the fairness argument on pay for play isn't a fair argument. Huffington Post.

Brand, M. (2009, January 15). The challenges of commercial activity. State of the Association Address. https://mylesbrand.com/wp-content/uploads/2009/01/200 9-NCAA-State-of-the-Association.pdf

Feezell, R. (2015). Branding the role and value of intercollegiate athletics. Journal of the Philosophy of Sport, 42(2), 185-207.

Matz, L. (2020). Turning intercollegiate athletics into a performance major like music. Journal of the Philosophy of Sport, 47(2), 283-300. 